\title{
Inclusion body myositis
}

INSERM

\section{Source}

INSERM. (1999). Orphanet: an online rare disease and orphan drug data base. Inclusion body myositis. ORPHA:611

Inclusion body myositis (IBM) is a slowly progressive degenerative inflammatory disorder of skeletal muscles characterized by late onset weakness of specific muscles and distinctive histopathological features. 